\title{
Understanding the Practices and Experiences of Supervising Nursing Doctoral Students: A Qualitative Survey of Two South African Universities
}

\author{
T. M. Mothiba ${ }^{1}$, M. S. Maputle ${ }^{2} \&$ D. T. Goon ${ }^{3}$ \\ ${ }^{1}$ Faculty of Health Sciences Executive Deans Office, University of Limpopo, Sovenga, South Africa \\ ${ }^{2}$ Department of Advanced Nursing Science, University of Venda, Thohoyandou, South Africa \\ ${ }^{3}$ Department of Nursing Science, University of Fort Hare, East London, South Africa \\ Correspondence: T. M. Mothiba, Department of Nursing Science, University of Limpopo, Sovenga, South Africa.
}

Received: October 28, 2018 Accepted: March 18, 2019 Online Published: May 10, 2019

doi:10.5539/gjhs.v11n6p123 URL: https://doi.org/10.5539/gjhs.v11n6p123

\begin{abstract}
Doctoral supervision involves an intensive, interpersonal one-to-one relationship between the supervisor and the student. Supervisors have a responsibility to guide students when choosing their research topics and throughout the research process until completion of their research projects. The purpose of this study is to explore the practices and experiences of faculty members supervising doctoral nursing students in two selected universities in South Africa. This qualitative and explorative study involves all faculty members supervising doctorate nursing students at four South African Universities in Limpopo Province. A purposive sampling was used to select 15 participants who met the inclusion criteria. Data collection was through a telephonic in-depth unstructured interview. Probing was used to elicit more information from participants. Data were analysed through Tesch's open coding method. Findings reveal three themes as practices and experiences of supervision, namely: research supervisory role, knowledge of models of supervision, and guiding principles towards doctorate supervision. There is a need for orientation of research supervisors and doctoral students before they commence with their supervisory role. Policies and procedures for doctorate supervision need to be communicated to all supervisors. There should be continuous support for both supervisors and students during the process of supervision.
\end{abstract}

Keywords: supervision, practices, experiences, supervisors, doctoral students

\section{Introduction}

Supervision at the doctorate level involves an intensive, interpersonal one-to-one relationship between the supervisor and the student. Research supervisors need to consciously engage with their students who are contemplating academic careers. Supervisors have a responsibility to guide students in choosing research topics and in navigating through the research process until completion of their research projects. Supervisors must offer guidance and support and build capacity in students for developing presentations, writing for a range of audiences and publishing their work (Jepsen, Verhagyi, \& Edward, 2012; Greer, Cathcart, \& Neale, 2016). It is therefore expected that research supervisors must have the relevant skills to be able to execute their supervisory roles which might assist students to overcome any obstacles during the research process (Parnell, 2006). The execution of the relevant research supervisory role should ultimately result in the realisation of the students' aim, which is to complete their degrees. This would contribute to the university students' throughput (Abiddin, Hassan \& Ahmad, 2009). The supervision process entails a one-to-one relationship between supervisor and student. The relationship of the student and the supervisor is dependent on a number of variables which include the student-supervisor relationship; the student's commitment and the responsibility of the student to manage his/her own learning in order to graduate (Abiddin, Hassan, \& Ahmad, 2009).

James and Baldwin (1999) outline doctoral supervision practices to which supervisors and students should adhere. Prior to the beginning of the supervision process, there is need to assess the student and to clarify roles and responsibilities. This practice sets in motion the supervisory procedure. The supervisor motivates and assists the student to overcome challenges during the research journey. However, conflicts might arise as students encounter different expectations of conducting research and this might have a negative impact on the learning experience (Guerin, Green, \& Bastalich, 2011; Manathunga \& Goozee, 2012; Lahenius \& Ikavalko, 2014; Guerin \& Green, 
2015).

Supervisors may choose from several models of supervision to assist students to complete their doctoral research projects, bearing in mind the different needs and individual differences of the students. However, it should be noted that students' needs might change as their research progresses because it is envisaged that students develop into independent researchers; as this occurs, supervisors should be willing to allow students greater autonomy. The uni-dimensional model encompasses a list of expected traits. This model assists supervisors to understand and practise their supervision in a liberal, humanistic manner as they exhibit transparency during engagement with the doctoral students (Delany, 2010).

A study conducted in South Africa recommends training postgraduate supervisors on a continuous basis; constantly collaborating with supervisors from other universities to share supervisory experiences. In addition, it recommends the drafting of institutional guidelines on supervision which should be constantly referred to during the supervision process to address the challenges of postgraduate supervision (Lessing \& Schulze, 2003). Furthermore, another study conducted in South Africa suggests that research supervisors need to deal with their previous style of supervision so that is does not impact negatively on the current supervision process. The study suggests that supervisors use their knowledge and understanding of their roles in supervision to continually improve their research supervision skills (Nsibande, 2007).

Madikizela-Madiya, Goba and Nkambule (2013) advocate creating a postgraduate supervision environment which is non-coercive, whereby the supervisor does not necessarily control the student, but plays a liberal or moderating role in the supervision process. It was further suggested that the supervision environment be seen as a sustainable learning environment, with an empowering effect, promoting values of democracy and social justice for the student to take a lead in their research projects. Anecdotally, faculty members, involved in the supervising of doctorate nursing students in South African universities, have expressed varying supervisory practices and experiences concerning their engagement with the students. Some supervisors indicate some students could not differentiate between a researchable and a non-researchable topic. Given this kind of naivety, the supervisor ends up suggesting a research topic for these students. Some students struggle to complete their research because of academic, social and personal challenges, while others end up quitting. In some cases, the students are frustrated by the supervisors because of a lack of cooperation or a hostile relationship. Faced with such situations, supervisors and students alike adopt several measures to save the bad situation. However, these unempirical narratives have seldom been investigated. The purpose of this study is to explore the practices and experiences of faculty members supervising doctoral nursing students in two selected universities in South Africa.

\section{Methods}

The study used a qualitative and explorative approach to determine the practices and experiences of faculty members concerning the supervising of doctorate nursing students in four selected universities in order to gain more knowledge about doctoral supervision, based on the meaning outlined by the supervisors themselves. In order to achieve the descriptive part of this study the supervisors were given an opportunity to describe and explore their supervisory roles and experiences during the supervision process (McMillan \& Schumacher, 2010). The researchers explored the phenomenon by asking questions about doctoral supervision leading to explicit information provided by the participants during the telephonic interview sessions (Babbie \& Mouton, 2009; Brink, 2012).

\subsection{Population and Sample}

The population comprised all faculty members involved in the supervision of doctoral nursing students in the four selected South African Universities in Limpopo Province. A purposive sampling was used to select participants who met the inclusion criteria: those who hold a doctorate qualification supervised or co-supervised more than two doctorate candidates and were willing to participate in the study. This method was used because researchers relied on available participants with knowledge about the phenomenon studied (de Vos, Strydom, Fouché, \& Delport, 2011; Babbie \& Mouton, 2009).

\subsection{Data Collection}

Data were collected by the use of telephonic unstructured interviews. During the interview sessions, the researchers asked one main question: "Can you please explain your experience in supervising a doctorate candidate?" The question was followed by probing to elicit more information about the phenomenon studied (de Vos, Strydom, Fouche, \& Delport, 2011). A total of 15 supervisors voluntarily agreed to participate in the study. However, only 12 participants were interviewed until data saturation was reached. 


\subsection{Data Analysis}

Data was analysed through Tesch's open coding approach (Botma, Greeff, Mulaudzi, \& Wright, 2010). The interviews' verbatim transcripts were systemically organised for each interview session, then the transcripts were analysed which resulted in getting a sense of the whole of all the transcripts. The thoughts which emerged were noted, similar topics were clustered and abbreviated into codes, and finally, the researchers established the themes and sub-themes which reflected the practices and experiences of the doctorate supervisors.

\subsection{Trustworthiness}

Trustworthiness was ensured throughout the study through the criteria of credibility, dependability and transferability, as outlined by Babbie and Mouton (2009). The credibility, the truth value, was ensured by developing a trusting relationship when setting appointments and during data collection from the supervisors. The methodology used was exhaustively explained so that other researchers would be able to replicate the study.

\subsection{Ethical Standards and Procedures}

Participants were informed by email about the aim and purpose of the study, as well as all the processes to be followed. The informed consent forms were sent to the participants to sign if they agreed to participate. Confidentiality and anonymity of the participants were ensured by not using their names on any document of this research project.

\section{Results}

Table 1. Demographic profile of doctoral supervisors recruited to the study

\begin{tabular}{|c|c|c|}
\hline Midwives & Number & Percentage \\
\hline \multicolumn{3}{|l|}{ Gender } \\
\hline Male & - & - \\
\hline Female & 15 & 100 \\
\hline \multicolumn{3}{|c|}{ Qualifications } \\
\hline $\mathrm{PhD}$ & 9 & 60 \\
\hline D Cur & 4 & 27 \\
\hline \multicolumn{3}{|c|}{ Duration of $\mathrm{PhD}$ qualification in years } \\
\hline $2-4$ & 8 & 54 \\
\hline $5-6$ & 5 & 33 \\
\hline$>7$ & 2 & 13 \\
\hline \multicolumn{3}{|c|}{ Number of $\mathrm{PhD}$ students supervised } \\
\hline $0-2$ & 13 & 87 \\
\hline $2-4$ & 2 & 13 \\
\hline $5-6$ & - & - \\
\hline \multicolumn{3}{|c|}{ Number of completed PhD students } \\
\hline $0-2$ & 13 & 87 \\
\hline $2-4$ & 2 & 13 \\
\hline
\end{tabular}


Table 2. Representation of the themes and sub-themes reflecting the practices and experiences of doctoral supervisors

\begin{tabular}{llll}
\hline Themes & \multicolumn{2}{l}{ Sub-themes } \\
\hline Views related to research supervisory & - & Research supervisory role viewed as mentorship \\
role & - & Provision of support to candidates a necessity \\
& & - & Supervisory role viewed as a teaching role \\
Knowledge related to models of & - & Lack of knowledge versus knowledge existence related to models of supervision \\
supervision & & - & Description of supervision models used \\
Guiding principles towards doctoral & - & Knowledge related to University's supervision policies and procedures \\
supervision & - & Circumstances of the time dictates the type of supervision \\
& & &
\end{tabular}

\section{Views related to research supervisory role}

The descriptions given by the participants during the telephonic interview sessions revealed the views related to research supervisory roles for doctoral supervisors. The results indicate that the supervisors view their role as that of a mentor to their students. An excerpt from one participant states: "I also view myself as a mentor because I have to guide the students throughout the research process and guide them towards the finishing line through motivation." Another participant with the same view said: "I was a mentor to my PhD students who completed because I had to provide support to them until completion of their PhD programmes. My mentorship included providing them with guidance throughout the process and being a teacher when they were stuck and they didn't have knowledge with some of the aspects and supporting them when they needed it."

\section{Provision of support to candidates a necessity}

It is evident from the study findings that doctoral students need support from their supervisors through the research which is the key to completion of their research projects. The participant who indicated that support is important outlined that: "My role as supervisor as being that of a leader in the project, and I support my students throughout the time of the project in order for them to complete." Another participant with the same opinion said: "I support my students throughout being under my supervision because if you don't provide that support you will not have PhD students completing under your supervision. PhD is quite frustrating it needs a supervisor who can be able to support his/her students during the supervision process."

Supervisory role viewed as a teaching role

Supervisors should see their role as intertwining with teaching research concepts to students. In areas where the student does not understand, the supervisor needs to teach difficult and unclear research concepts and aspects to clear those research ambiguities. The following excerpt highlights this: "I perceive my role as supervisor to be that of providing the student with guidance regarding the research process. The process starts with the development of a proposal and ends with the writing of the research report. My role is also to educate the student about the research process so that there is logical coherence between the purpose of the study and the research process".

\section{Knowledge related to models of supervision}

The study findings reveal that some supervisors have knowledge related to supervision models, while some do not possess the required knowledge. Two sub-themes emerged under this theme: lack of knowledge versus knowledge related to models of supervision and descriptions of supervision models used. Some doctoral supervisors have knowledge related to models of supervision that they need to use during the supervision of students' research projects. A participant expressed his lack of knowledge about supervision models as follows: "Yes, the model is based on reviewing the student's work, make suggestions, and refer the student to literature where I realise there is lack of understanding of the research process and the content of what the student is researching. I expect the student to implement all the suggested corrections and if there are differences between myself and the student, the student is free to argue and not take my recommendations." Another participant who has knowledge about the models of supervision said: "I use Co-supervision model and for few students I used individual supervision. I used most of my time one-on-one/individual supervision because most people by the time I supervised PhD's people didn't have PhD's in the department I am working in to can qualify to supervise a PhD. Therefore, it was impossible to have a co-supervisor." 
The participants described the various supervision models they applied in supervising students. These were clarified by the participant who said: "There are three supervision models that I know and they are amongst the one I use. I use co-supervision model, the other one that I know is individual supervision but I don't like it because when this supervisor has a problem it will mean that the student will suffer. The last one that I know is group supervision whereby a group of students are supervised by a group of supervisors. This [last mentioned model] supervision method is in big funded projects where several objectives are to be achieved in one project."

\section{Guiding principles for doctoral supervision}

According to this theme, findings reveal that there should be written guidance for supervisors of postgraduate students, including those who supervise doctoral students. Three sub-themes emerged from this theme (Table 2). Participants indicated that in order to effectively supervise a doctoral student, supervisors need to be conversant with the supervision policies of their institution. This is suggested in the following excerpt: "I think as a supervisor I need to be guided by the university on several levels which include being given research supervision policies, conducting briefing sessions whereby important supervision aspects are highlighted by the university research unit and lastly being included in workshops or courses offered related to research supervision role." Another participant said, "It is unfortunate that as supervisors we don't really know what the university expects from us but there are few policies that we know but during the process of supervision you are also asked to submit or do other things that don't appear in the policies. It is better to be trained on all aspects related to supervision."

The findings reveal that sometimes the supervisor finds him/herself in situations where he/she needs guidance. The findings were confirmed by the participant who said: "Supervision is channelled by circumstances and situations which you find yourself in during supervision. For example, as a supervisor you supervise according to the students' needs, level of knowledge and the personality." Another participant confirms this notion saying: "If you meet an unpleasant situation during your supervision that assist you develop a skill on how to handle that problem at hand because sometimes you find that the university policy don't address that aspect."

The study reveals that there is a need to get a briefing about what the supervision role entails before starting the process. This was highlighted by the participant who said: "I suggest in every department or faculty in a university setting they explain the supervisory role to new supervisors before they allocate them students to supervise. This must be done at all levels of supervision, which is undergraduate and postgraduate level." Another participant of the same view said: "Supervisors must be orientated what is expected from them to void simple mistakes to occur."

\section{Discussion}

This present study explores the practices and experiences of faculty members supervising doctoral nursing students in two selected universities in South Africa. Generally, the findings showed the faculty members have varying supervisory practices and experiences concerning their engagement with the students. Madikizela-Madiya, Goba and Nkambule (2013) outline that research supervision must be seen by the researcher supervisors as a way of mentoring students towards gaining confidence in conference presentations and writing research papers for publication. There is need for support when choosing the topic for doctorate research (Taylor \& Beasley, 2005; Kiley, 2009). Moses (1992) maintains that supervisors should act as mentors, and should strive for mutual respect based on high academic standards, and regular contact, besides having solid background of research involvement and publications. Supervisors should be able to mentor students towards presenting papers in conferences, co-writing reports to funders and co-writing journal articles for publications for them to achieve their research expectations and function independently (Madikizela-Madiya et al., 2013). In this regards, large academic research projects could be utilised for mentoring up-and-coming academics in order to enhance their research skills and academic career. As research progresses, the relationship of students and supervisors move from direction and guidance towards the formation of a critical friendship (Connell, 1985).

Often, when students fail to complete their studies in the required period, they tend to blame their supervisors (McClure, 2005; Terrell, Snyder \& Dringus, 2009), and "failure" of not getting through a doctoral programme could be devastating (Krauss \& Ismail, 2010). Of course, the nature of supervision experienced by the student under the supervisor has an influence on the success or otherwise of the student's completion of the research work in a reasonable time (Lahenius \& Martinsuo, 2009; Felton, 2006). The research conducted by Donald, Saroyan and Denison (1995) shows that constant availability and thoughtfulness during supervision was the key to successful graduate completion. Spear (2000) concludes that complaints from research students concerned infrequent or erratic contact with supervisors. His findings were that supervisors were viewed as too busy with administrative or teaching responsibilities or as having too many students or as being away from the university too often. Therefore, the supervisors should make equal information, time and energy available to all students (Brown \& Krager, 1985) and should meet regularly with students (Russell, 1996; Hockey, 1996). Lessing and Lessing (2004) outline factors 
that might facilitate the students' completion of postgraduate research; one factor that was mentioned was the provision of personal and collegial support. It was further indicated that students need support with the research process and research techniques as a whole.

The findings indicate that the supervisory role in research also includes teaching. Bitzer (2010) concurs with these findings by indicating that there is a need for research training during the supervision of postgraduate research projects. Phillips and Pugh (2000) point out that the acquisition of skills by postgraduate students should be professionally conducted under their own management. The authors emphasise the need for the students to take responsibility in managing their own learning to complete their doctoral programmes by regularly keeping in touch with their supervisors (Moses, 1992; Powles, 1989). Supervisors expect students to be diligent, hardworking, energetic, keen, tenacious and conscientious and to demonstrate a sense of urgency (Moses, 1992). Students are expected to display enthusiasm and to be motivated towards research work. They must be pleasant at their work and should contribute to a good working environment. Supervision is a two-way process; students are expected to give continual feedback so that the supervisor can give informed instruction. Generally, the experienced supervisors were seen to use more teaching and sharing behaviours which encourage supervisees to be more active. Good supervisors seemed to have qualities of good lecturers and good counsellors (Norhasni, Aminuddin, \& Abdul, 2009).

Lee (2007) outlines several models of research supervision. These include the functional model where effective supervision is done guided by an instruction manual with information about research process and qualities of the model. This identifies the qualities of a good supervisor which include emotional intelligence and flexibility, both important in working with postgraduate students. Supervisors should possess the research knowledge and skills to achieve effective supervision (Donald, Saroyan, \& Denison, 1995; Sheehan, 1994; McQueeney, 1996; Powles, 1989), and provide counselling to students they supervise (Zuber-Skerrit, 1994). Since supervision is a two-way process, students expect supervisors to possess the knowledge and the ability to supervise their research projects effectively. Students also expect supervisors to be reasonable, approachable and supportive of their work at all times (Moses, 1994).

During the supervision process, supervisors should provide timely feedback to students in order forestall unnecessary delays. Constructive feedback is of benefit during supervision, since it builds students' self-esteem. However, if the feedback is negative, it may damage their confidence (Halse, 2011; Wang \& Lee, 2011; Aichison $\&$ Mowbray, 2013). Positive feedback should be given when appropriate, in clear messages, and be actionable for the progress of the project (McAlpine, 2013).

Many challenges confront the supervisor in the process of supervising nursing doctoral students. According to Strauss (2012), in order to minimise the challenges experienced during supervision, supervisors need to be educated as to how they can communicate with their students during the supervision process. The study conducted by Roets and Maritz (2013) finds that students who experienced problems during research supervision had to create opportunities which could sustain them towards the completion of their degree when conducting research. These included creating a constructive learning environment and developing affirmative personal attributes. The Council on Higher Education (2009) states six factors associated with non-completion of postgraduate studies in South African universities. These factors are: poor planning and management, methodological difficulties, writing-up, isolation, personal problems outside research and inadequate or negligent supervision. The non-completion of studies contributes to a low graduation rate. The Council on Higher Education (2009) reports that the South African average annual growth of doctorate graduates is only $6 \%$, approximately $45 \%$ of doctoral students who enrol never complete their studies, and 29\% drop out within the first two years.

Delamont, Atkinson and Parry (2004), Eley and Murray (2009) concur that to remedy the ugly situation of poor supervision and dropout rates of doctoral studies, orientation sessions on supervision to support both supervisor and student/s, are crucial and needed. In preparation for the session, the agenda should include clear objectives, processes, outcomes and arrangements for supervision. Supervisors need to be trained about supervisory systems and practices which will complement research and supervision needs for the supervisors to be effective. To further ensure the effective supervision journey, supervisors are urged to create opportunities for supervisors to orientate students as to available resources to help with undertaking their research projects, to prevent delay on research progress. During supervision, students should be made aware of resources and sources of academic support, including issues relating to research integrity.

\section{Conclusion and Recommendations}

It is evident from the study findings that faculty members, supervising doctorate nursing students, exhibit varying practices at different levels of and understanding during the supervision process. This causes uncertainties during 
their supervisory role. There is a need to orientate research supervisors about their expected roles and responsibilities, the supervisory model unique to the university, as well as about any anticipated challenges in the course of the supervision process. Equally, the students need to know what their roles and expectations are, the policies and procedures involved and the communication channels available. There should be continuous support for both supervisors and students during the process of supervision.

\section{Competing Interests Statement}

The authors declare that there are no competing or potential conflicts of interest.

\section{References}

Abiddin, N. Z., Hassan, A., \& Ahmad, A. R. (2009). Research student supervision: An approach to good supervisory practice. Open Edu J, 2, 11-16. https://doi.org/10.2174/1874920800902010011

Aitchison, C., \& Mowbray, S. (2013). Doctoral women: managing emotions, managing doctoral studies. Teaching Higher Edu, 18(8), 859-870. https://doi.org/10.1080/13562517.2013.827642

Babbie, E., \& Mouton, J. (2009). The practice of Social Research. Cape Town: Oxford University Press.

Ballard, B., \& Clanchy, J. (1993). Supervising students from overseas. J Higher Edu, XXV(3), 1-29.

Bitzer, E. M. (2000). Supervising Higher Degrees as a scholarly practice. South Afri J Higher Edu, 21(8), 1010-1019.

Botma, Y., Greeff, M., Mulaudzi, F. M., \& Wright, S. C. D. (2010). Research in Health Sciences. Cape Town: Heinemann.

Brink, H. (2012). Foundation of research methodology for health care professionals (3rd edition). Cape Town: Juta.

Botha, N. (2010). Practices in postgraduate research supervision: from apprentice to scholar. Acta Acad Supplementum, (1), 57-74.

Brown, R. D., \& Krager, L. (1985). Ethical issues in graduate education: faculty and student responsibilities. $J$ Higher Edu, 56(4), 403-418. https://doi.org/10.1080/00221546.1985.11780701

Burns, N., \& Grove, S. K. (2009). The practice of nursing research: Appraised synthesis and generation of evidence (6th ed.). Philadelphia: Saunders.

Connell, R. (1985). How to supervise a PhD. Vestes, 2, 38-41.

Council on Higher Education (2009). Higher Education monitor no.8: The State of Higher Education in South Africa. Retrieved 2017, December 6, from http://www.che.ac.za/media_and_publications/monitoring-and-evaluation/higher-education-south-africa-dat a-2009

De Vos, A. S., Strydom, H., Fouché, C. B., \& Delport, C. S. L. (2011). Research at grass roots for the social science and human service professions (4th ed.). South Africa: Van Schaik.

Delamont, S., Atkinson, P., \& Parry, O. (2004). Supervising the Doctorate - a Guide to Success. Maidenhead: Open University Press.

Delany, J. (2010). Students' perceptions of effective teaching in Higher Education. Paper presented at the 26th Annual Conference of Teaching and Distance Learning, San Francisco.

Donald, J. D., Saroyan, A., \& Denison, D. B. (1995). Graduate student supervision policies and procedures: A case study of issues and factors affecting graduate study. Can J Higher Edu, XXV-3.

Donald, J. G., Saroyan, A., \& Denison, D. B. (1995). Graduate student supervision policies and procedures: a case study of issues and factors affecting graduate study. J Higher Edu, XXV(3), 71-92.

Eley, A., \& Murray, R. (2009). How to be an effective supervisor. Maidenhead, Open University Press.

Felton, S. (2005). Student experiences of supervision: Student-supervisor agreement. Retrieved June 18, 2017, from http://www.lancsac.uk/celt/celtweb/currentjournal

Greer, D., Cathcart, A., \& Neale, L. (2016). Helping doctoral students teach: Transitioning to early career academia through cognitive apprenticeship. Higher Edu Res Dev, 35(4), 712-726. https://doi.org/10.1080/07294360.2015.1137873

Guerin, C., \& Green, I. (2015). 'They're the bosses': feedback in team supervision. J Further Higher Edu, 39(3), 
320-335. https://doi.org/10.1080/0309877X.2013.831039

Guerin, C., Green, I., \& Bastalich, W. (2011), Big Love: Managing a Team of Research Supervisors. In Kumar, V. \& Lee, A. (eds.) Doctoral Education in International Context: Connecting Local. Regional and Global Perspectives. Malaysia, University Putra Malaysia.

Halse, C. (2011). 'Becoming a supervisor': the impact of doctoral supervision on supervisors' learning. Stu Higher $E d u, 36(5), 557-570$. https://doi.org/10.1080/03075079.2011.594593

Hockey, J. (1996). Strategies and tactics in the supervision of UK social science PhD students. Int J Qualitative Stud Edu, 9(4), 481-500. https://doi.org/10.1080/0951839960090409

James, R., \& Baldwin, G. (1999). Eleven practices of effective postgraduate supervisors (1st ed.). University of Melbourne, Victoria: Centre for Higher Education and the School of Higher Education.

Jepsen, D., Verhagyi, M., \& Edward, D. (2012). Academics' attitudes towards PhD students' teaching: preparing research higher degree students for and academic career. J Higher Edu Policy Man, 34(6), 629-645. https://doi.org/10.1080/1360080X.2012.727706

Kiley, M. (2009). Identifying threshold concepts and proposing strategies to support doctoral candidates'. Innov Edu Training Int, 46(3), 293-304. https://doi.org/10.1080/14703290903069001

Krauss, S. E., \& Ismail, I.A. (2010). PhD student experiences of thesis supervision: "Management" as an acceptable strategy and strategy for action. Pertanika J Soc Sci Hum, 18(1), 157-166.

Lahenius, K., \& Ikavalko, H. (2014). Joint supervision practices in doctoral education - A student experience. $J$ Further Higher Edu, 38(3), 427-466. https://doi.org/10.1080/0309877X.2012.706805

Lahenius, K., \& Martinsuo, M. (2009), Different types of doctoral processes in industrial engineering and management. In The 20th NFF Conference, August 19-21, Turku Finland. 15.

Lee, A. (2007). Developing Effective supervisors. South Afr J Higher Edu, 21(4), 680-693.

Lessing, N., \& Lessing, A. C. (2004). The supervision of research dissertation and theses. Acta Commercii, 4(1), 73-87. https://doi.org/10.4102/ac.v4i1.54

Madikizela-Madiya, N., Goba, B., \& Nkambule, T. (2013). Developing a research identity: A reflective narration of postgraduate students' supervision experiences in research project. South African J Higher Edu, 27(4), 941-952.

Mananthunga, C., \& Goozee, J. (2007). Challenging the dual assumption of the 'always/ already' autonomous student and effective supervisor'. Teaching Higher Edu, 12(3), 3019-322.

McAlpine, L. (2013). Doctoral supervision: Not an individual but a collective institutional responsibility. $J$ Study Edu Dev, 36(3), 259-280. https://doi.org/10.1174/021037013807533061

McClure, (2005). Reflection on practice. Retrieved June 18, 2017, from www.practicebasedlearning.org

McMillan, J. H., \& Schumacher, S. (2010). Research education: evidenced-based inquiry (7th ed.). Boston, MA: Pearson.

McQueeney, E. (1996). The nature of effective research supervision. J Further Higher Edu Scotland, 20(1), 23-31.

Moses, I. (1992). Good supervision practice. J Higher Edu, XXV(3), 1-29.

Moses, I. (1994). Supervision of Higher degree students - problem areas and possible solutions. Higher Edu Res Dev J, 3, 153-165. https://doi.org/10.1080/0729436840030204

Norhasni, Z., Abiddin, H., \& Abdul, R.A. (2009). Research students' supervision: An approach to good supervisory practice. Open Edu J, 2, 11-16. https://doi.org/10.2174/1874920800902010011

Nsibande, R. (2007). Using 'currere' to re-conceptualise and understand best practices for effective research supervision. South Afr J Higher Edu, 21(8), 1117-1125.

Parnell, J., \& Prendergast, P. J. (2006). Postgraduate Supervision: Best practice guidelines on research supervision for academic staff and students. Retrieved June 15, 2017, from http://www.tcd.ie/Graduate_Studies/docs/Supervison\%20Guidelines.pdf

Phillips, E. M., \& Pugh, D.S. (2000). How to get a PhD - a handbook for students and their supervisors. Buckingham: Open University Press.

Powles, M. (1989). How's your thesis going? J Higher Edu, XXV, (3), 1-29. 
Roets, L., \& Maritz, J. E. (2013). Challenges, opportunities and achievements of nurses' research supervision across language borders. Afr J Phys, Health Edu, Recrea Dance (Supplement 1, September), 68-79.

Russell, A. (1996). Postgraduate research: student and supervisor views. The Flinders University of South Australia.

Sheehan, P. (1994). From thesis writing to research application: learning the research culture. J Further Higher Edu Scotland, 20(1), 23-30.

Spear, R. H. (2000). Supervision of research students: responding to student expectations. Canberra. The Australian National University.

Strauss, P. (2012). The 'English is not the same': challenges in thesis writing for second language speakers of English. Teaching Higher Edu, 17(3), 283-293. https://doi.org/10.1080/13562517.2011.611871

Taylor, S., \& Beasley, N. (2005). A handbook for doctoral supervisors. London, Routledge Falmer. https://doi.org/10.4324/9780203415740

Terrell, S., Snyder, M., \& Dringus, L. (2009). The development, validation, and application of the doctoral student connectedness scale. Internet in Higher Education, 12(2), 112-116. https://doi.org/10.1016/j.iheduc.2009.06.004

Wang, T., \& Li, L. (2011). 'Tell me what to do vs. 'guide me through it' Feedback experiences of international doctoral students. Active Learning Higher Edu, 12, 101-102. https://doi.org/10.1177/1469787411402438

Zuber-Skerrit, O. (1994). Improving the quality of postgraduate supervision through residential staff development programmes. J Further Higher Edu Scotland, 20(1), 23-30.

\section{Copyrights}

Copyright for this article is retained by the author(s), with first publication rights granted to the journal.

This is an open-access article distributed under the terms and conditions of the Creative Commons Attribution license (http://creativecommons.org/licenses/by/4.0/). 